\title{
Size Confirmation and Stability Analysis of Mine Panel Pillars
}

\author{
Dan Huang ${ }^{1,2, a}$, Xiu-zhi Shi'1,b ${ }^{* 1}$ Ting Guo ${ }^{1, c}$ \\ ${ }^{1}$ School of Resources and Safety Engineering, Central South University, Changsha, China; \\ ${ }^{2}$ Beijing General Research Institute of Mining \& Metallurgy, Beijing, China;

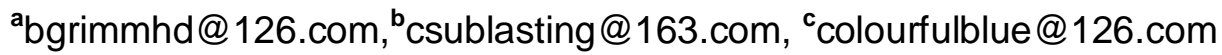

Keywords: panel pillars, stability, numerical modeling, reliability analysis, size of ore pillars

Abstract. When exploiting large-scale ore-body, stability of panel pillars is the key to stability of structural support mechanical system of ore pillar-surrounding rock. It concerns the mining sequence of the ore-body, parameters of stope structure, and is a problem that must be considered to some mines of safety and economic exploitation. This paper applied numerical modeling and reliability analysis to study mechanical characteristics and the safety coefficients of antidumping and strength in the process of mine exploitation. And the size of panel pillars were determined synthetically, that provided technical support to the safe, economic and high-efficient mining.

\section{Introduction}

Large-scale ore-bodies are generally divided to panels and exploited by multi-panel house-jamb separation to realize high-efficient mining, such as Fankou Lead Zinc Mine, Lilou Iron Ore, Mount-Isa Lead Zinc Mine, Dongguashan Copper Mine, and JiaMa Copper Mine, etc. Underground mining will cause secondary stress that filed inside the rock mass constantly overlays, which possibly arouses deformation or buckling failure of the panel pillar. The stability of the panel pillars is the key of mechanical system of support structures such as pillar-surrounding rock in mines ${ }^{[1-5]}$. This paper applies numerical simulation to calculate the width of penal pillars, and uses reliability theory to judge reliability and safety of the panel pillar. The technique and method to reasonably determine the size of panel pillar and analyze stability of structure of rock mass was proposed.

\section{Reliability Analysis of Panel Pillar}

Consider the uncertain influencing factors in mining as stray parameters ${ }^{[6]}$. Based on interior, site test data, and using statistical method, the statistical law of all influential factors was analyzed. The reliability of the project was presented by failure probability of system.

Monte Carlo Analysis Principle ${ }^{[7,8]}$. Reliability of engineering structure is the probability to complete expected function within the fixed time and conditions ${ }^{[9]}$. In process of analyzing reliability of ore pillar, the limit equilibrium state equation of ore pillar can be explained through performance function:

$$
Z=g\left(x_{1}, x_{2} \mathrm{~L}, x_{n}\right) .
$$

$x_{i}(i=1,2 \mathrm{~L} n)$ is the random variable affecting reliability of the jamb, and its influencing factors include compressive strength, unit weight of rock mass, etc. $Z>0$ means that the jamb is in safe state; $Z=0$ means the jamb is in limit critical state; $Z<0$ means the buckling failure of jamb occurs. When $\mathrm{Z}$ is less than 0 , probability of the jamb to lose stability is: 


$$
p=\int \mathrm{L} \int f_{x}\left(x_{1}, x_{2} \mathrm{~L}, x_{n}\right) d x_{1} \mathrm{~L} d x_{n} \text {. }
$$

By virtue of reliability theory to calculate reliability index of panel pillar, the parameters affecting jamb is considered as random variables. Through setting up limit state equation of jamb to carry out anti-dumping and strength reliability analysis, the relationship between width of jamb $(W)$ and reliability indicators and safety coefficient is obtained.

Mechanical analysis of panel pillars. With the exploitation, the sides of the panel pillars have been gradually turned into fillings or goafs. In a copper mine, the stope is regressively mined from hanging side to heading side. In this process, hanging stopes of the panel pillar may have been filled; the heading stope may be goafs, which is the most unfavorable state for the stability of panel pillars. Fig. 1 and Fig. 2 show respectively the modeling notation and stress schematic plot under the most unfavorable conditions for the panel pillar stability. $F_{1}$ is the force imposed on the fillings, which increase in linear along with the depth; $F_{2}$ refers to force of upper surrounding rock acted on the jamb; $G$ is the gravity itself.

$$
\begin{aligned}
& F_{1}=\frac{1}{2} \gamma h^{2} K_{a} . \\
& G=\gamma_{b} H W .
\end{aligned}
$$

$h$ is the height of the fillings, and $H$ is the height of the stope. The result of $F_{2}$ can be calculated by numerical simulation: $F_{2}=\sigma A$.

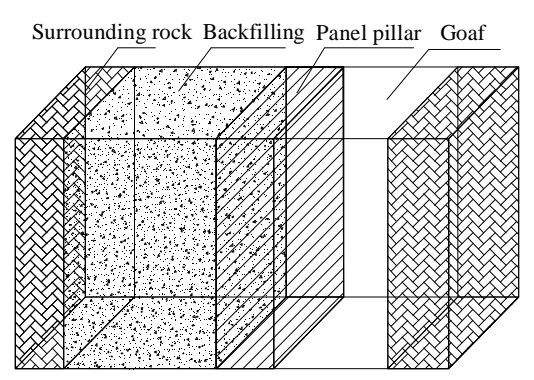

Fig.1 Modeling Notation of Panel Pillar

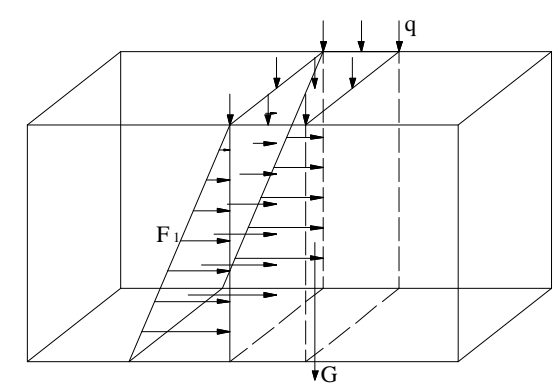

Fig. 2 Stress Schematic Plot of Panel Pillar

Limit state equation of jamb. On the basis of safety factor calculated by fixed value method, select some parameters as random variables, and set the safety factor calculated by fixed value as 1. Then the limit state equation of corresponding analysis methods can be drawn, that is to analyze the reliability.

(1) Limit state equation under anti-overturning conditions. To ensure that the jamb will not overturn under the pressure action of the filling of hanging stope. Setting:

Anti-overturning moment:

$$
R=G \frac{W}{2}+F_{2} \frac{W}{2} \text {. }
$$

Overturning moment:

$$
S=F_{1} \frac{H}{3}
$$

Limit condition of anti-dumping $R \geq S$, its corresponding limit state equation is: 


$$
g_{1}(x)=G \frac{W}{2}+F_{2} \frac{W}{2}-F_{1} \frac{H}{3}=\left(\gamma_{b} H W+\sigma A\right) \frac{W}{2}-\frac{1}{2} \gamma H^{2} K_{a} \frac{H}{3} \text {. }
$$

Factor of safety against overturning:

$$
K=\frac{R}{S}=\frac{G \frac{W}{2}+F_{2} \frac{W}{2}}{F_{1} \frac{H}{3}} \text {. }
$$

(2) Strength condition limit state equation. Vertical load effect of jamb $S=\sigma_{1 x}+\sigma_{2 x}$, and $R=\sigma_{c}$. The maximum conditions of strength is $R \geq S$. The limit state equation of the corresponding strength conditions is:

$$
g_{2}(x)=R-S=\sigma_{c}-\left(\sigma_{1 x}+\sigma_{2 x}\right) .
$$

Strength safety coefficient

$$
F=\frac{R}{S}=\frac{\sigma_{c}}{\sigma_{1 x}+\sigma_{2 x}}
$$

\section{FLAC $^{3 \mathrm{D}}$ Numeric Simulation Scheme}

Numeric Simulation Scheme. A large-scale copper ore is mined by panel exploiting. The stopes are basically arranged vertically, and the sequence of mining adopts the backward mining method from ends to the center. This numeric modeling takes the 9 stopes in 3 panels as the study object. After the stopes of 1\#, 2\# panel in the hanging side is filled, the 3\# panels starts to excavate, when the panel pillar is at the most dangerous state. Select five types of jamb width of $26 \mathrm{~m}, 28 \mathrm{~m}, 30 \mathrm{~m}$, $32 \mathrm{~m}, 34 \mathrm{~m}$, through simulating, the displacements and vary of plasticity areas are analyzed in this process ${ }^{[10]}$. By studying the state that most unfavorable to the stability of panel pillar, analyze the stability of the jamb, and thus calculate the reasonable width of the panel pillars.

Geometric modeling and mesh generation. The size of modeling is $880 \mathrm{~m} \times 240 \mathrm{~m} \times 400 \mathrm{~m}$. The distance of surface of the model from the earth's surface is $400 \mathrm{~m}$. There are 41184 mold elements and 45425 nodes. 3D-calculation model is shown in Fig. 3.
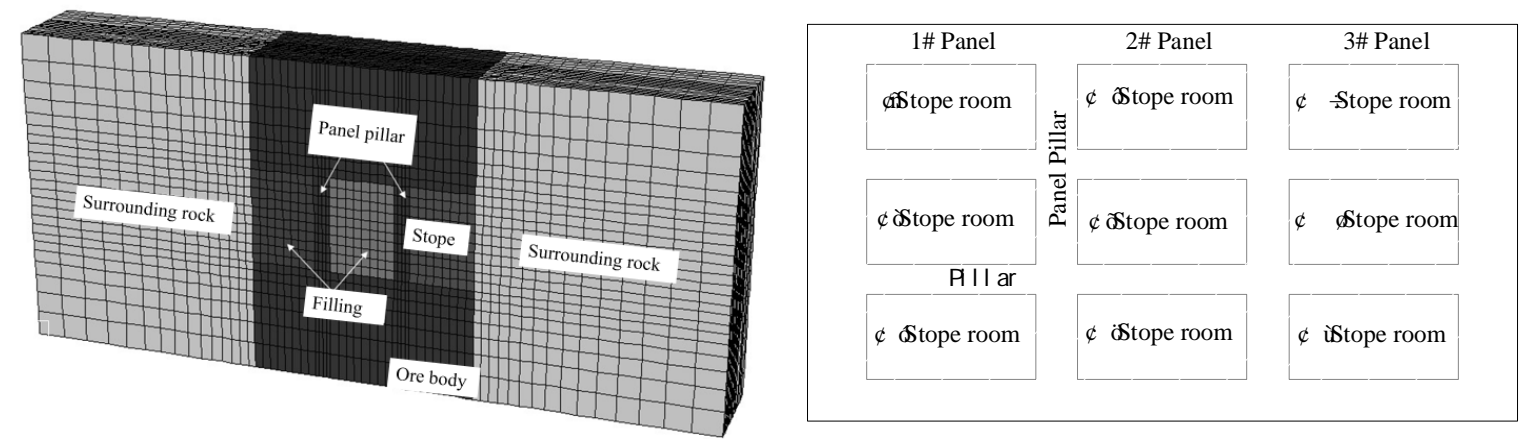

Fig. 3 3D-calculation model and plan sketch of panel pillar FLAC ${ }^{3 \mathrm{D}}$

Material parameter. Rock mass mechanics parameters of a cooper mine is shown in Table 1. The filling station of the mine is under construction, which lacks tailings sampling conditions. With reference to domestic test data about mechanical parameters of filling materials, the mechanical parameters concluded is as shown in Table 2:

Layout of the supervision point. The stope of this copper mine is of higher stage long-span 
room, the roof and sides of the stope are the critical locations which are liable to stress concentration. 13 supervision points are set up in the simulation calculation to record the stress and displacement variations. The supervision points (Fig. 4) record and track from the room mining till the end of the whole simulation calculation ${ }^{[9]}$.

Table 1 Mechanical parameters of rock mass

\begin{tabular}{ccccccc}
\hline Lithology & $\begin{array}{c}\text { Binding } \\
\text { power } \\
{[\mathrm{MPa}]}\end{array}$ & $\begin{array}{c}\text { Internal } \\
\text { friction } \\
\text { angle } \\
{\left[{ }^{\circ}\right]}\end{array}$ & $\begin{array}{c}\text { Strength } \\
\text { of } \\
\text { extension } \\
{[\mathrm{Mpa}]}\end{array}$ & $\begin{array}{c}\text { Elasticity modulus } \\
{[\mathrm{GPa}]}\end{array}$ & Poisson's ratio & $\begin{array}{c}\text { Density } \\
{\left[{\left.\mathrm{g} . \mathrm{cm}^{3}\right]}^{3}\right.}\end{array}$ \\
\hline $\begin{array}{c}\text { Quartz-diorite-porphyry } \\
\text { (including copper mine) }\end{array}$ & 1.98 & 37.92 & 4.87 & 38.25 & 0.25 & 2.81 \\
$\begin{array}{c}\text { Quartz-diorite-porphyry } \\
\text { (major roof and floor rock } \\
\text { mass) }\end{array}$ & 3.64 & 41.45 & 3.22 & 34.64 & 0.30 & 2.70 \\
\hline
\end{tabular}

Table 2 Filling material parameters

\begin{tabular}{|c|c|c|c|c|c|c|}
\hline $\begin{array}{l}\text { Type of } \\
\text { fillings }\end{array}$ & $\begin{array}{c}\text { Unit } \\
\text { Weight } \\
{\left[\mathrm{g} / \mathrm{cm}^{3}\right]}\end{array}$ & $\begin{array}{c}\text { Strength of } \\
\text { extension } \\
\sigma_{t}[\mathrm{Mpa}]\end{array}$ & $\begin{array}{l}\text { Elasticity } \\
\text { modulus } \\
\text { E[Mpa }]\end{array}$ & $\begin{array}{c}\text { Poisson's ratio } \\
\mu\end{array}$ & $\begin{array}{c}\text { Binding } \\
\text { power } \\
C[\mathrm{Mpa}]\end{array}$ & $\begin{array}{c}\text { Internal friction } \\
\text { angle } \\
\varphi\left[{ }^{\circ}\right]\end{array}$ \\
\hline $1: 4$ & 1.83 & 0.40 & 573.03 & 0.20 & 0.546 & 35.7 \\
\hline $1: 8$ & 1.74 & 0.17 & 231.10 & 0.22 & 0.21 & 30.3 \\
\hline $\begin{array}{l}\text { Whole } \\
\text { tailings }\end{array}$ & 1.74 & 0 & 18.0 & 0.30 & 0.0095 & 26.5 \\
\hline
\end{tabular}

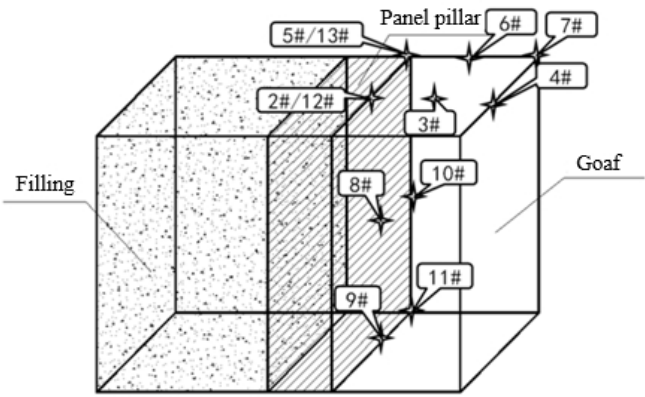

Fig. 4 Layout of supervision point

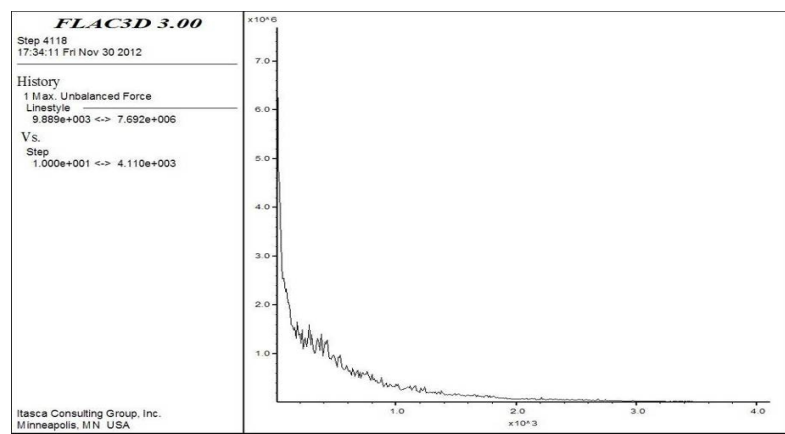

Fig. 5 The maximum balance force sampling record chart

\section{Numeric Simulation Calculation Result Analysis}

Maximum unbalanced force analysis of the system. It can be seen from Fig. 5, the maximum unbalanced force of the system is gradually level off to 0 along with the calculation, which means the system finally reaches the balanced state. In the convergence procedure, the mutation degree is small, which means no stress mutation occur in the operation process. Therefore, the excavation simulation step can be conducted.

Stope excavation simulation and displacement analysis. By analyzing the simulated results, the widths of $26 \mathrm{~m}, 28 \mathrm{~m}, 30 \mathrm{~m}, 32 \mathrm{~m}, 34 \mathrm{~m}$ respectively, the displacement changing curve of the critical points of the roof and panel pillar of the $\square \#$ stope is as shown in Fig. 6, and 7. The 3\# and 8\# monitoring points are located in the center of the stope roof and panel pillar. The displacements is much greater comparing with other monitoring points, that is, displacements in center of stope roof and panel pillar are the greatest. The vertical displacements of stope roof and the horizontal displacements of the panel pillar under different widths of $3 \#$ and $8 \#$ monitoring points are recorded, as shown in Fig. 8 and 9. 


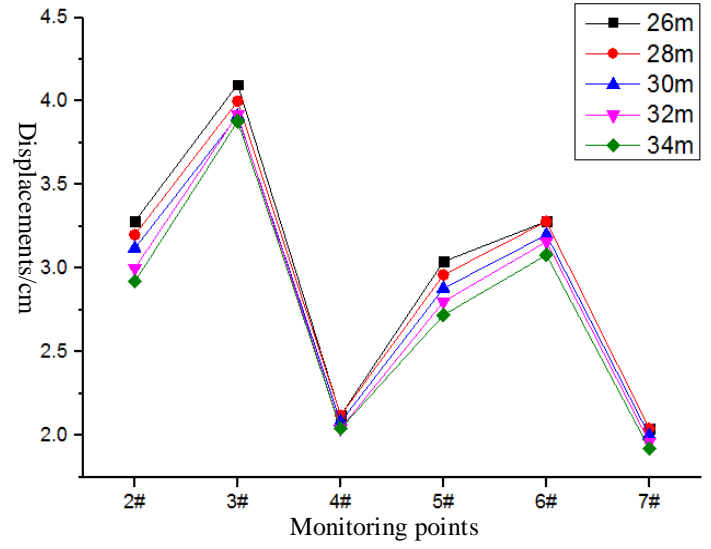

Fig. 6 Vertical displacement of panel pillars of different widths

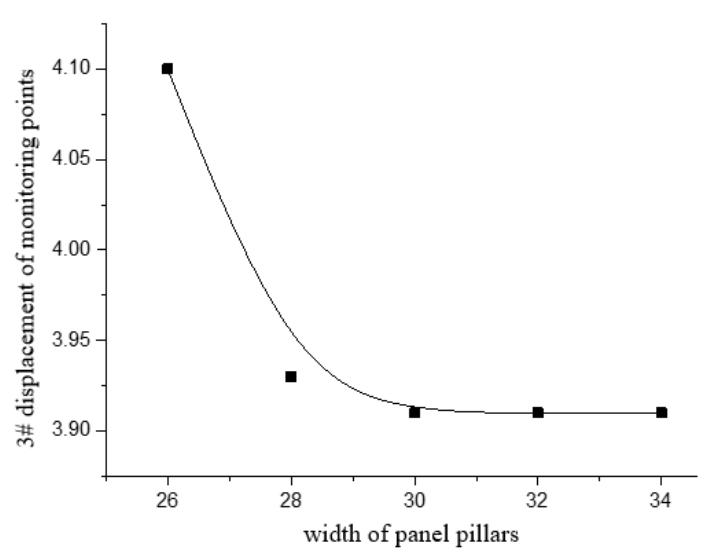

Fig. 8 Vertical displacement of 3\# monitoring point with different widths

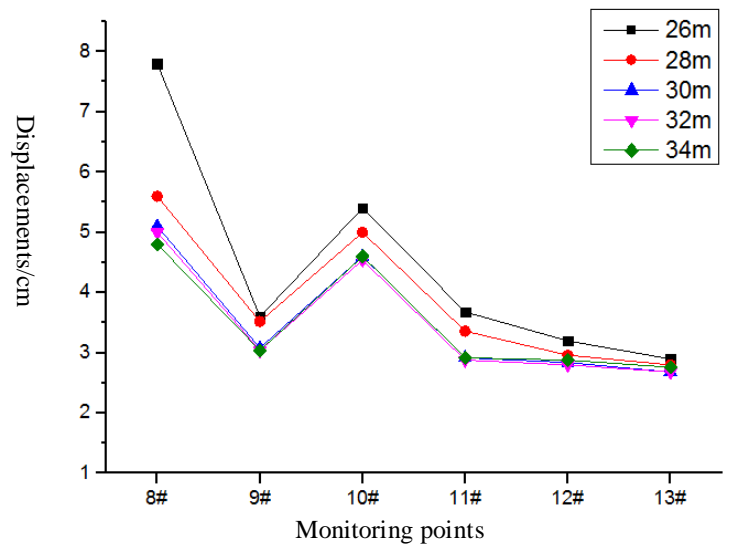

Fig. 7 Horizontal displacement of panel pillars of different widths

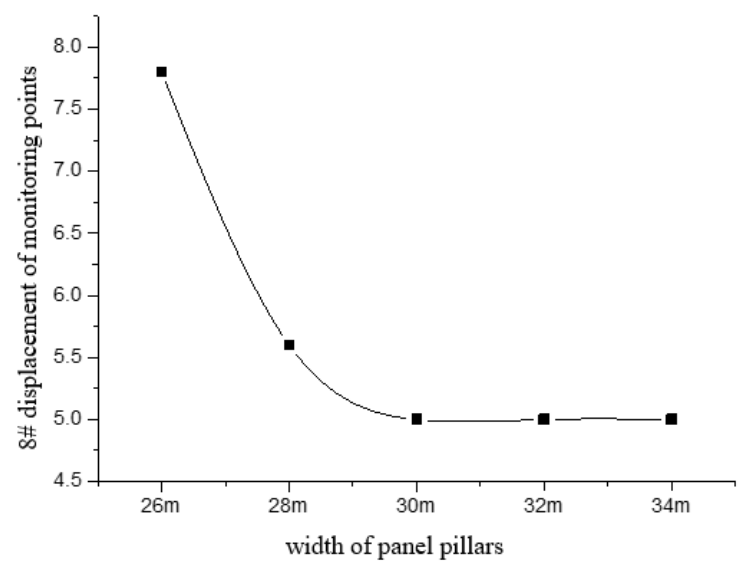

Fig. 9 Vertical displacement of $8 \#$ monitoring point with different widths er of different widths

According to the features of the displacement changing curve, assume that the displacements of monitoring points and the width of the panel pillars meet the form of Taylor's series curve, then select the form of fitting curve equation as follows:

$$
V(W)=a_{0}+a_{1}(W)+a_{2}\left(W^{2}\right)+a_{3}\left(W^{3}\right) .
$$

$a_{0}, a_{1}, a_{2}, a_{3}$ are the undetermined coefficients of the polynomial; $W$ is the width of panel pillar; $V$ is the displacement.Taking the derivative of Eq. 11, get $V^{\prime}(W)$. The research result shows: when $V^{\prime}(W)$ is smaller than 0 , displacement vary rapidly, which is considered that the panel pillar is in unstable state and damage may happen; when $V^{\prime}(W)=0$ the displacement variation levels off, which is considered that the panel pillar is stable and no damage happen.

$$
\Delta=a_{1}+2 a_{2} W+3 a_{3} W^{2}=0 .
$$

Match the displacement curve in Fig. 8 and Fig. 9 respectively based on Eq. 11 and 12 , and the results are shown in Table 3.

It can be seen from Fig. 8 and 9: when width of the jamb is $20 \mathrm{~m}$ to $28 \mathrm{~m}$, the displacements fall dramatically; when it is $30 \mathrm{~m}$ to $34 \mathrm{~m}$, the displacement levels off as a whole, and fluctuates slightly. The displacements have shown that when the width of the jamb is smaller than $30 \mathrm{~m}$, the width affects the stability greatly, when it is bigger than $30 \mathrm{~m}$, the width affects the stability little. Analyzing from displacement angle, it can be judged that $\Delta=0$, width of the panel pillar should be 
$28 \mathrm{~m}, 35 \mathrm{~m}$ and $29.57 \mathrm{~m}$ respectively. Therefore, $W=30 \mathrm{~m}$ can be considered as the turning point of the displacements. Analyzing from displacement angle, width of the panel pillar is at least $30 \mathrm{~m}$.

Table 3 Fitted results of displacement curve of 3\# and 8\# monitoring point

\begin{tabular}{ccccccc}
\hline Monitoring point & $\mathrm{a}_{0}$ & $\mathrm{a}_{1}$ & $\mathrm{a}_{2}$ & $\mathrm{a}_{3}$ & $\begin{array}{c}\text { Coefficient of } \\
\text { associationR }\end{array}$ & $\begin{array}{c}\text { Criteria } \\
\Delta=0\end{array}$ \\
\hline 8\#horizontal & 40.47 & -3.465 & 0.109 & -0.001 & 0.9956 & $\mathrm{~W}=29.35$ \\
displacement & 2 & 3 & 2 & 1 & & \\
3\# vertical & 19.41 & -16.07 & 0.450 & -0.004 & 0.9969 & $\mathrm{~W}=29.57$ \\
displacement & 9 & 4 & 9 & 2 & & \\
\hline
\end{tabular}

Stope excavation simulation and plastic zone analysis. Analyze the deformation of plastic zone under widths of the panel pillar which is shown in Fig. 10. The statistical analysis of the deforming shear-n and tension- $\mathrm{n}$ is shown in Fig. 11.

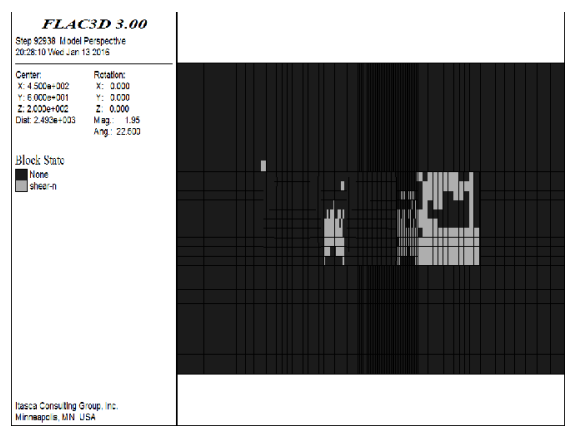

( a ) $26 \mathrm{~m}$

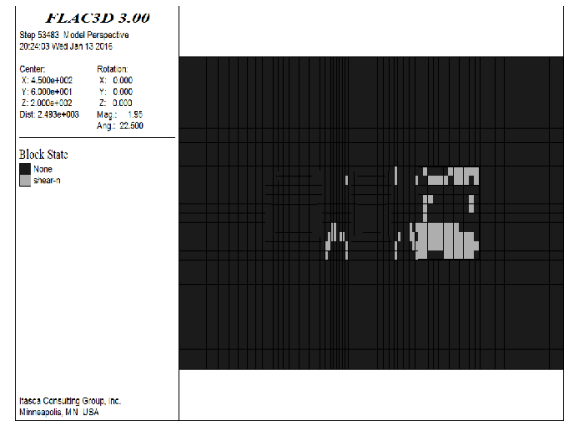

(c ) $30 \mathrm{~m}$

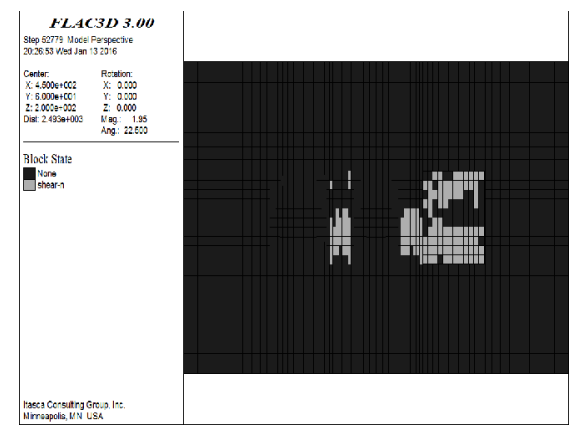

(b) $28 \mathrm{~m}$

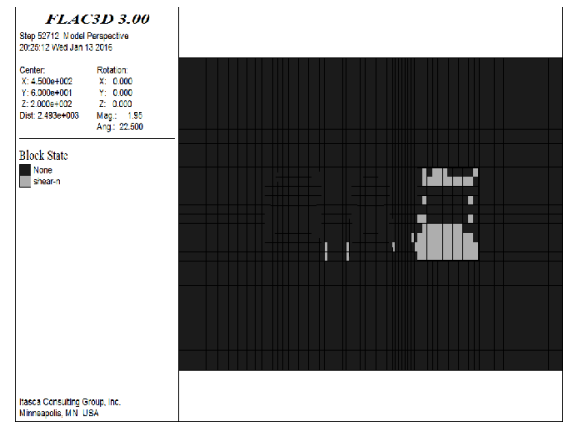

(d) $32 \mathrm{~m}$

Fig. 10 Deformation zone of shear-n under different widths of panel pillars

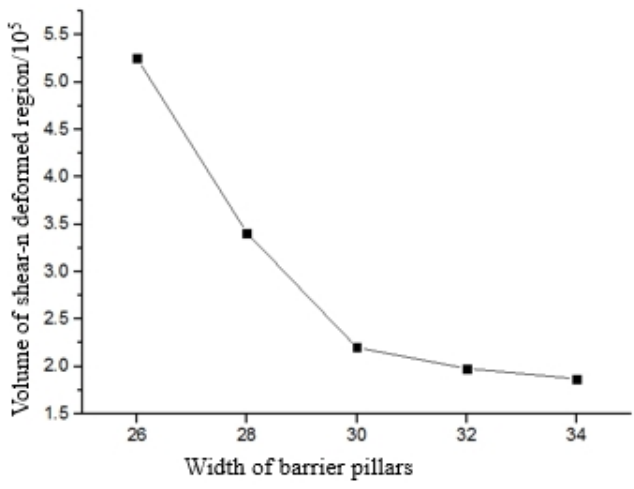

Fig. 11 Volume of deformed region shear-n under different widths of panel pillars

From Fig. 10, when the width is $26 \mathrm{~m}, 28 \mathrm{~m}$, the plastic zone of panel pillars of hanging side 
and footwall may be cut through in large area, and the volume of plastic deformed zone is big. The panel pillars will lose stability. When the width is $30 \mathrm{~m}$, its plastic zone is not cut through and volume of plastic zone is small, which shows that the panel pillars is stable. From Fig. 11, when the panel pillars is $32 \mathrm{~m}, 34 \mathrm{~m}$, the volume of plastic zone is almost the same to the volume of plastic zone when it is $30 \mathrm{~m}$, and its variation tendency levels off. So we can say the width of $30 \mathrm{~m}$ is more reasonable.

\section{Calculation of reliability indicator of panel pillar}

Factors affecting stability of panel pillar is numerous, such as size of jamb structure, compressive load, material parameter of the mineral and rock, etc. All these factors are random variables. It is know from literature [2], that unit weight $\gamma_{b}$ of the mine, compressive strength $\sigma_{c}$ and unit weight of the fillings $\gamma$ are considered as the random variables affecting the stability of panel pillar the most remarkably, which is regarded as normal distribution. Under the random variables with given distribution, average values and variable coefficients, by utilizing the Monte-Carlo value simulation, we can achieve the reliability indicators of anti-dumping limit state equation and strength limit state equation, which is shown in Table 4.

Table 4 Relationship between pillar widths and reliability indicators of anti-dumping and strength

\begin{tabular}{ccccccc}
\hline & & & \multicolumn{2}{c}{ Anti-dumping } & \multicolumn{2}{c}{ Strength condition } \\
\cline { 4 - 6 } No. $\begin{array}{c}\text { Width } \\
\text { of pillar }\end{array}$ & Width/Height & $\begin{array}{c}\text { Anti-dumping } \\
\text { reliability indicator } \\
\beta_{1}\end{array}$ & $\begin{array}{c}\text { Anti-dumping } \\
\text { safety factor } \mathrm{F}_{\mathrm{s} 1}\end{array}$ & $\begin{array}{c}\text { Ultimate strength } \\
\text { reliability factor } \beta_{2}\end{array}$ & $\begin{array}{c}\text { Strength } \\
\text { safety factor } \\
\mathrm{F}_{\mathrm{s} 2}\end{array}$ \\
\hline 1 & $20 \mathrm{~m}$ & 0.17 & 1.9198 & 1.1227 & 1.8231 & 0.9987 \\
2 & $22 \mathrm{~m}$ & 0.18 & 2.3571 & 1.2454 & 2.1878 & 1.1089 \\
3 & $24 \mathrm{~m}$ & 0.20 & 2.6291 & 1.3680 & 2.3898 & 1.2028 \\
4 & $26 \mathrm{~m}$ & 0.22 & 3.1513 & 1.4919 & 2.7861 & 1.3508 \\
5 & $28 \mathrm{~m}$ & 0.23 & 3.6706 & 1.6169 & 3.0762 & 1.4253 \\
6 & $30 \mathrm{~m}$ & 0.25 & 3.9836 & 1.7444 & 3.6838 & 1.5878 \\
7 & $32 \mathrm{~m}$ & 0.27 & 4.4302 & 1.8739 & 4.1537 & 1.7238 \\
8 & $34 \mathrm{~m}$ & 0.28 & 4.8769 & 1.9593 & 4.5276 & 1.8328 \\
\hline
\end{tabular}

From Table 4, we know that: (1) The reliability and safety indicators of anti-dumping, strength increase along with the increase of width-height ratio of panel pillars, and the variation tendency of the two indicators are the same. Value of anti-dumping indicator is bigger than the value of strength indicator. (2) According to the retaining wall theory, the safety coefficient of jamb is above 1.5. Based on the reliability indicator of the limit state of the carrying capacity of the architectural structure members, the third-level standard of brittle failure is at least $3.2^{[6]}$. Analyzing from anti-dumping angle, the width of panel pillar should be above $28 \mathrm{~m}$, while if measure safety of the panel pillar by strength condition indicators, the width of jamb is at least $30 \mathrm{~m}$. Above all, it is suggested to take the width of panel pillar as $30 \mathrm{~m}$.

\section{Conclusion}

(1) Adopting FLAC ${ }^{3 \mathrm{D}}$ to set up ore-body model under different widths of panel pillars, and by tracking and recording the stress-displacement variation rule of 13 critical locations of the ore-body model, the displacement variation and plastic damage method of the panel pillar in mining process was studied comparatively. By analyzing the stability of different sizes of panel pillar, the width of panel pillar is at least $30 \mathrm{~m}$.

(2) By virtue of principle of reliability theory, utilizing Monte-Carlo simulation to calculate the 
anti-dumping indicator and strength condition limit indicator of panel pillars, and combining the calculation results of two indicators, we have verified the numeric simulation result, and finally determined the width of the panel pillar as $30 \mathrm{~m}$.

(3)Through numeric simulation and reliability analysis, the economic and reasonable size of the panel pillar was comprehensively determined, that provided technical support to safety and efficient mining of the ore body.

\section{Acknowledgments}

This work was financially supported by Project supported by National Science and Technology Support Program (2013BAB02B05).

\section{References}

[1] Wang Yungang, Wei Jianping, Sun Haitao: Mining Safety \& Environmental Protection, Vol.37(2010), p.17-19. (In Chinese)

[2] Li Dexian,Wang Yongcai: Jinchuan Sceince and Technology, Vol.3(2008), p.9-14. (In Chinese)

[3] Li Qichang. Mining technology for retreat the protecting ore body under Jinyang Road. Central South University, 2004. (In Chinese)

[4] Guo Li, Wu Aixiang, Hu Jiaguo, etc. Metal Mine, Vol.3(2003), p.4-7. (In Chinese)

[5] Zhang Bao. Pillar stability analysis and visual verification in deep mining. Central South University, 2009. (In Chinese)

[6] Gu Desheng, Deng Jian, Li Bingxi: Engineering Sciences, Vol.1(2001), p.51-57. (In Chinese)

[7] Tortorella: Iie Transactions, Vol.34(2002), p.1111-1114.

[8] Dong Lei. Study on optimum design of stope structure parameters and reliability analysis. Central South University, 2010. (In Chinese)

[9] Duan Wenfu. The analysis of cutting slope stability based on the reliability. Wuhan University of Technology, 2008. (In Chinese)

[10] Zhao Xingdong: Chinese Journal of Rock Mechanics and Engineering, Vol.29(2010), p.2616-2622. (In Chinese) 